\title{
Stromal Invasion
}

National Cancer Institute

\section{Source}

National Cancer Institute. Stromal Invasion. NCI Thesaurus. Code C35954.

A term referring to the presence of tumor emboli or tumor masses within the stroma of an organ. 